Session 1380

\title{
Graduate Physics Education - Industrial Style
}

\author{
Ken Vickers, Greg Salamo, Ronna Turner \\ University of Arkansas
}

\begin{abstract}
The education and training of the workforce needed to assure global competitiveness of American industry in high technology areas, along with the proper role of various disciplines in that educational process, is currently being re-examined. Several academic areas in science and engineering have reported results from such studies that revealed several broad themes of educational need that span and cross the boundaries of science and engineering ${ }^{1-5}$. They included greater attention to and the development of team-building skills, personal or interactive skills, creative ability, and a business or entrepreneurial where-with-all.

While many engineering programs around the country have embraced some of these needs with unique programs, physics has lagged far behind and has tended to maintain its traditional basic science education. Rather than these needs being a goal of a traditional physics graduate program, we tend to instead produce students trained in the conventional sense. Students strong in basic understanding but with little or no interpersonal skills. Students ignorant of business related issues, yet with problem solving skills needed by business. And, above all, students very comfortable in an academic environment, but unsure of how to effectively use their academic expertise in a non-academic arena.
\end{abstract}

The University of Arkansas in the fall of 2000 received a Department of Education Fund for Improvement of Post Secondary Education (FIPSE) grant to implement changes in its graduate physics program to address these issues. The proposal goal is to produce next-generation physics graduate students that are trained to evaluate and overcome complex technical problems by their participation in courses emphasizing the commercialization of technology research. To produce next-generation physics graduates who have learned to work with their student colleagues for their mutual success in an industrial-like group setting. And finally, to produce graduates who can lead interdisciplinary groups in solving complex problems in their career field.

In this paper we will present the evidence that led to the specific strategic plans that were proposed to the department of education, strategic plans that will be used to achieve the goal of physics graduates from the University of Arkansas with enhanced technology implementation skills. The early implementation status through March 2001 will also be discussed, along with specific near 
term milestone events leading to full program startup for the academic year 2001-2002.

\section{Introduction}

The Physics Department at the University of Arkansas took the broad themes identified as being needed in future graduate students and translated them into a set of four specific goals for the FIPSE program implementation. They were:

a) Integrating traditional physics education with a business framework

b) Integrating traditional physics education with creativity training

c) Integrating global perspectives into local technology decisions

d) Integrating soft skill set development with traditional physics education

The University of Arkansas was awarded its Department of Education FIPSE grant in Fall 2000 under PIs Greg Salamo (Physics), Ken Vickers (Physics), and Ronna Turner (Education Research). The expected outcome of the work under this grant is the creation of a new process by which next-generation physics graduates are trained to evaluate and overcome complex technical problems by participating in courses emphasizing the commercialization of technology research. To produce next-generation physics graduates who have learned to work with their student colleagues for their mutual success in an industrial-like group setting. And finally, to produce graduates who have learned to lead interdisciplinary groups in solving complex problems in their career field.

The University of Arkansas Physics Department will accomplish these aggressive goals through an innovative combination of a traditional physics curriculum, an industry-like work environment shared by physics students in this program, and a commercialization course sequence centered on a Physics Department's research strengths (at the University of Arkansas, it will be based on research in high performance microelectronic-photonic materials, devices, and systems). The integration of these three educational components will result in a next-generation Physics graduate with the skills currently lacking from traditional Physics departmental programs.

a) Integrating traditional physics education with a business framework.

Technology proficiency will not be sufficient to assure that future scientists and engineers make proper decisions, or to assure that they are successful in their personal careers. They must also be able to work effectively in areas outside of their technical expertise, as they are no longer allowed to exist in an isolated technical environment. The fact is that many products require a high level of technical sophistication to even evaluate if it is the proper product for a given application.

As a result, today there must be more interaction between the developers of a new technology product and the customer. The scientist or engineer is therefore forced into active participation in such areas as customer negotiations, marketing and business planning, and manufacturing support. 
While their need for technical competence is not being reduced to support their primary task, their need for other non-technical knowledge is being increased by the many secondary roles that they are being asked to play.

From the large industry perspective, the need for a broadened knowledge base in their scientists and engineers lies in the broad financial impact of the decisions they will make. In a survey of manufacturing engineering jobs, Mason reports that "The results... also emphasize the importance of a broad education. Engineers need to be technically proficient at their job and at the same time understand the economic and engineering implications of their decisions." ${ }^{2}$. The Boeing Company CEO Philip Condit has stated that "... it is important that engineering education also have breadth. Students need to know about business economics: What does it cost to build a project? What's involved in integration?" 6 .

On the other end of the business size spectrum, small entrepreneurial technology startups are requiring their smaller employee base to not only develop the technology, but also to manufacture and market it. Robert Morgan has reported the results of a meeting of fifty leaders of the National Academy of Engineering (NAE) that "Engineering employment in manufacturing has moved somewhat from large companies to medium and smaller ones, including many start-up businesses. These workforce changes have created a demand for engineers who can fuse technical, managerial, financial, and industrial skills" 7 . The same attendees noted that future technologists “... need a breadth of knowledge to handle complex objectives and multidisciplinary functions, to understand non-engineering issues, and to perform systems engineering in a loosely bound environment".

Using the FIPSE grant support, the University of Arkansas will provide its next-generation Physics students with academic exposure to non-technical management-related courses, a mentored experience in an entrepreneurial environment, and practical seminars and workshops to examine both the financial and ethical side of technology decisions. Specific objectives incorporate the students developing business plans to evaluate the potential marketability of applications or products created during structured classroom activities. In this way we will meet our objective of the theoretical knowledge gained through traditional academic being clarified and integrated into the students' personal skill set through their efforts to productize their own creative efforts.

b) Integrating traditional physics education with creativity training

Next-generation Physics students have a need to concentrate on the ever-deepening body of knowledge in a technical specialty. This may be viewed as being in conflict with the need for a scientist or engineer to be able to integrate information from many technical fields into a solution to a specific problem that is faced. But in several high technology fields, a study of deep-level knowledge can itself becoming multidisciplinary. As was noted in the NAE workshop, the engineering intensity of products is increasing because of a closer coupling of engineering and science, especially at the molecular level, where the distinctions between the sciences and the 
various engineering disciplines blur ${ }^{7}$.

For instance, in integrated circuit process development, a technologist must understand the intrinsic nature of the materials (physics), the dynamic equilibrium of the processing reactors (chemical engineering), the physical properties of the multiple layers (mechanical engineering), and the needed characteristics of the final devices (electrical engineering). A student graduating with a degree in any of these fields would have deep knowledge of one aspect of the problem solution, but little knowledge of the other needed areas. As this industry progresses through the sub-micron range into nanometer scale devices, it will become even more difficult to separate the science from the engineering of the devices.

While it is impossible for students to become a deep level expert in all technical areas, it is possible for students in a flexible physics program to select academic courses that will increase their ability to work intelligently with specialists from other areas. Joseph Bordogna, past deputy director and chief executive officer of NSF, has stated "cross-functional collaboration and multidisciplinary problem-solving, insofar as they tap individual creativity and enhance the range and quality of solutions, have grown equally essential to the success of the R\&D effort (as technical skills)" 8 .

At the same time one must not lose sight of the fact that the traditional American post-secondary education system is seen as very desirable to the world's students because it has produced many very successful and innovative graduates. In a survey of aerospace professionals in laboratory, academe, and industry, it was noted that the respondents were not in favor of eliminating current technical discipline boundaries as the base background for a student, but they did feel that they should be involved in interdisciplinary educational activities such as team design and team problem solving sessions ${ }^{1}$.

The University of Arkansas Physics department has recently redefined the academic requirements for their degrees to allow more curriculum flexibility, allowing students to better tailor a curriculum for their career goals. At the Master of Science level, a MS Physics degree requiring a core physics block and all physics electives was defined, along with a MS Applied Physics degree with the same core physics block but with electives in either engineering or physics courses allowed.

Even so, these changes only begin to address the need for changes in traditional physics curriculums because they concentrate only on flexibility in the academic courses. The need for graduates to be increasingly creative in the application of their academic knowledge has been left to apprenticeship-like on-the-job training by their research professors. While this is certainly valuable training, it lacks the systematic approach to teaching that we demand in our academic educational methods. This apprenticeship method of training physics student to unleash their creativity often results in inconsistent creativity skills in a department's graduate student population. 
Under the FIPSE grant, the Physics Department will fully utilize the academic redefinition that has already occurred as an enabling mechanism that will allow easier implementation of the experimental educational and training aspects of this plan. Other institutions attempting to implement the novel educational elements described in this proposal may be required to implement similar modifications to their degree definitions to fully gain the benefit of these elements.

c) Integrating global perspectives into local technology decisions

The Asian economic crisis of 1998 was a reminder that we are now at the forefront of a global economy. This is because the global nature of high technology industry has evolved from being an association of production facilities in countries around the world to being a true interactive developmental collaboration of individuals around the world on a daily basis. The interactions between these individuals in a global effort are both creative in the direct developmental sense, as well as strategic in providing critical local country perspectives in the product definition and marketing stages.

The need for individuals to work effectively with others around the globe drives a strong need for next-generation physics students to not only intellectually understand and accept, but also emotionally embrace, the potential negative impact that cultural differences between countries can introduce to the needed collaborative effort. Bella Poroberts of Lucent Technologies has described this need for cross-cultural sensitivity as “... engineering teams, and virtually all other functions throughout an organization, must be cross-culturally aware in order to leverage resources to develop, market, manufacture, and service increasingly complex products and services around the globe. Sensitivity to other cultures is a business need throughout the organization" ${ }^{9}$. A similar viewpoint was expressed by the participants at the NAE workshop when they said "This emerging global marketplace is creating new opportunities for international collaboration. (The changes driven by these opportunities) ensures that communication skills within an international, intercultural, context will require much more attention" 7 .

In order for students to operate effectively in a global technical marketplace, they must progress beyond academic acceptance of the potential impact of cultural variations. They must emotionally integrate the impact of other global frameworks into their own experience. One way to enhance this emotional integration is for students to develop strong professional and personal relations with students from other countries. But traditional Physics departments have few programs designed to force students from different cultural backgrounds to share academic experiences in a way that promotes the development of these professional and personal relations.

The UA Physics Department will create and implement operational procedures that force students from different cultural backgrounds to learn not only to understand each others' perspectives, but also to see the value created when these different perspectives are all brought to bear on a common 
problem.

d) Integrating soft skill set development with traditional physics education

The need for a student to have effective skills outside of academic training upon graduation has become of prime interest to prospective employers. These outside soft skills encompass everything from management-related skills such as project management and supervisory skills, to interpersonal skills such as effective communication and team problem solving.

The participants of the NAE workshop recognize the changing face of the technologist's career. They stated "During recent years, engineering has continued to evolve, resulting in what seems to be a very different career trajectory for engineers than even 20 or 30 years ago. Job change is more frequent. Engineers now work more in teams, and industry conducts less long-term fundamental research. Companies outsource more of their work, relying on their engineers to act more as managers of technology than as practitioners" 7 .

At the same time, the Society of Manufacturing Engineers has stated in its Manufacturing Education Plan that the top three gaps between their student's educational needs and their academic training are communication skills; teamwork skills; and favorable personal attributes, such as leadership ability, sensitivity to others, professionalism, integrity, global awareness, and analytical skills.

Betty White, The Boeing Company's director of engineering and technology support and university relations has said "We need engineering graduates with a broader perspective. Beyond discipline-specific needs, our engineers need communication skills, the ability to work in teams and to understand design and manufacturing processes, and a basic understanding of the context in which engineering is practiced" 4 .

While these findings were addressed toward engineering degrees, they could also be applied to next-generation physics students planning to work in industrial, academic, or governmental facilities on group level projects. With the complexity of today's basic and applied research and commercialization, it is a rare job that allows physics professionals to work in isolated laboratories.

The UA Physics Department will address the needed soft skills training through both traditional academic-based methods, as well as non-traditional industrial training methods. One nontraditional method will be the creation of a pseudo-industry workgroup under the direction of an industrial technology manager with world-wide experience. In this workgroup all the students report to both individual major professors/advisors as well as to the director of the pseudo-industry workgroup, and will be responsible for an educational factory producing a high quality output product (the students themselves). Our objective is to create an environment where workgroup level tasks create multiple opportunities for each student to routinely practice team consensus 
building, project management, oral presentations, persuasive speaking, etc., therefore giving each student the practice necessary to fully integrate these skills into immediately available tools for use on non-workgroup issues.

\section{Implementation}

In order to meet the objectives outlined above, the Physics Department is beginning in the Fall 2001 semester three specific strategies:

a. Implementation of a cohort-based graduate workgroup methodology based on operational models found in industry.

b. Development and implementation of a framework for formal business and creativity training through a device invention course examining of current research areas.

c. Development and implementation of a framework for business and creativity training through a device development and commercialization course based in departmental research strengths.

Each strategy will address more than one of the educational development needs already discussed in this paper.

The two classes in items $\mathrm{b}$ and $\mathrm{c}$ above will be placed in the physics graduate student curriculum as a bridge sequence between the Master of Science curriculum and the Ph.D. curriculum. Students exiting the graduate program will be encouraged to take the first course in the sequence as a method to increase their creative application of the theoretical knowledge they have gained in the traditional courses already taken. Students proceeding to $\mathrm{Ph}$.D. studies will be encouraged to take the second course as very applied training in reducing creative ideas to concrete results (an area not typically emphasized in traditional Ph.D. programs). These two courses will be used as physics electives in the MS and Ph.D. model curricula currently defined in the graduate catalog, and as such will required no modification of the degree description before implementation. Figure 1 graphically illustrates the interactions between these three program strategies and existing educational elements available to the students. 


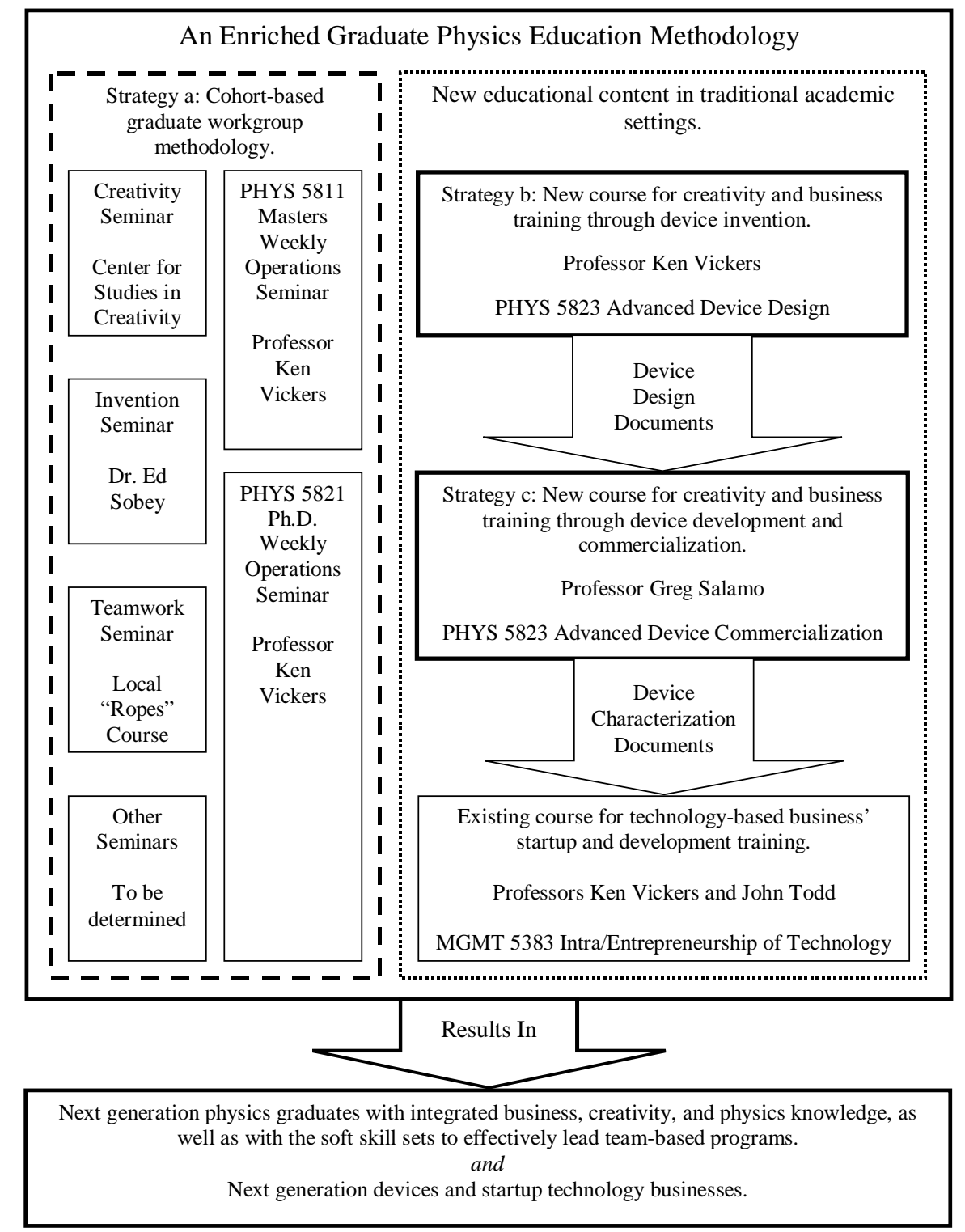

Figure 1: Interplay between Physics FIPSE program elements and current educational elements

a. Implementation of a cohort-based graduate workgroup methodology based on operational models found in industry.

This strategy addresses two of the identified educational needs: integrating global perspectives into local technology decisions and integrating soft skill set development with traditional physics education. The department will use traditional academic based methods, industrial training 
methods, and a non-traditional graduate program operational method based on an industry technology group model to accomplish this development. Academic short courses and industrial training methods designed to improve interpersonal skills already exist but are not typically utilized by traditional physics graduate programs. Using existing industrial seminars will demonstrate to the students the value and cost effectiveness of utilization of existing problem solutions rather than attempting to use local resources to create solutions to all identified problems.

But the key element that differentiates this program from other traditional physics graduate programs is its operational organization modeled on an industrial technology group. This organizational model is based on three concepts:

1. Each student reports to a direct supervisor (known as their Major or Research Professor) that oversees daily activities and progress toward research and educational goal achievement.

2. All students report in a "dotted line" manner to the director of their student cohort group who oversees group activities, program cohesiveness, and non-academic training elements.

3. All students report to each other as they form ad-hoc working groups in support of individual student support needs, group defined projects, or tasks assigned by the cohort director.

This model emulates the portions of an industry technology group that can be implemented in the academic environment. The major professor, seen as a direct supervisor, emulates the hierarchal reporting structure found in most technology companies' standing organizations. Each technologist in an industrial organization must maintain alignment with their direct supervisor to assure that their group objectives are being met.

At the same time, modern technology industry operates in a fluid management structure to meet short-term technology or business needs. These fluid management structures (or quasiorganizations) each have a project manager who is given partial management authority (known as "dotted line" authority) over appropriate technologists in multiple standing organizations. To create this dotted line authority structure in the graduate program, the physics department will place each academic year's entering students into a cohort group reporting to the graduate group director who will emulate the role of industrial project manager. Each student in order to graduate must learn to balance their work to meet the goals and objectives of both their major professor (focused on individual research) and the cohort director (focused on group level training and coordinated research activities).

Modern technology industry also depends on effective utilization of ad-hoc working groups that form to address local problems that are beyond the scope of an individual technologist to effectively address. These ad-hoc groups have lifetimes from days to months, are comprised of technologists with a combination of skill sets to address the problem, and whose chair is selected either by upper management or through group consensus. Similar ad-hoc working groups are 
formed within this graduate program operational model. For instance, a working group may be formed by the cohort director in order to create a solution to a problem common to all members of the cohort (such as management of shared office space). Other working groups may be formed by the cohort students (or even between cohorts) to focus multiple talents on a particularly difficult research problem element. Both of these types of ad-hoc groups emulate situations routinely found in industrial technology groups, and give the students experience in peer group leadership in support of group goals.

While this operational model is a simple concept, it provides the framework that allows the students to know each other well enough that they accept responsibility for each other's educational success. It also provides a framework to assign management responsibility for group needs to different students to organize and execute. This in turn provides multiple opportunities for each student to practice team consensus building, project management, oral presentations, persuasive speaking, etc., allowing the student to fully integrate these skills into immediately available tools for use after graduation.

This operational model is optimized if led by a person with experience in the industrial setting. At the University of Arkansas the graduate group director will be an experienced engineering manager from Texas Instruments (TI), Professor Ken Vickers. During his twenty-year career at TI, he developed operational skills in his primary job as engineering manager and worldwide team leader and demonstrated creative product development through his twenty-nine issued patents.

This work group structure creates the framework for the students developing an understanding of the impact global perspectives bring to technology issues. The director will hold weekly structured work group discussions on such diverse topics as cultural impact on industrial practices, research methods and their effectiveness, and opportunities for success in different work environments. Students will be asked to bring their local, internship, and international experiences to the table and compared with those of other students. This meeting will provide a mentored forum for candid discussions between the students concerning each student's cultural framework in which they view decisions.

During these weekly meetings, through their shared ad-hoc project groups, and through the identity they come to share as part of a unique cohort, the cohort members will come to know and trust each other. This will allow them to fully explore their emotional response to viewpoints brought by students from other cultures and to challenge whether the response has merit. In doing so, the students will develop practice in tolerance for other cultural frameworks and will be more likely to accurately identify and correct conflicts in the international business community that may be nothing more than a misalignment of observational frameworks.

Students in this graduate program will leave the university with a clear and personally experienced understanding of the value of cohesive team effort in support of individual and group goals. They will have emotionally integrated the value of educational and cultural diversity and the role that 
diversity plays in solving technology problems in internationally based technology research and industry.

b. Development and implementation of a framework for formal business and creativity training through a device invention course examining of current research areas.

This strategy will address three of the identified educational needs: integrating traditional physics education with a business framework, integrating traditional physics education with creativity training, and integrating soft skill set development with traditional physics education.

Integration of creativity training into the physics curriculum is the first priority of this action plan, which means that we must first define what we envision by the term creativity. We are referring to creativity as a "new idea", or in this sense creative ideas are the opposite of "conventional ideas" ${ }^{10-16}$. In physics, students learn to solve problems using tools or equations that are accepted as conventional. While problem solving is much more than simply substituting into equations, and while learning to use conventional tools to solve problems is the underpinning of physics, the educational experience would be much richer if it developed creativity. Although a traditional physics education plans the development of problem solving skills, the experience is not so well planned to develop (or at least unleash) creativity.

To plan the development of creativity the Physics Department will mobilize three student abilities ${ }^{17-27}$ :

- Synthetic ability is the ability to generate novel and interesting ideas. The creative individual uses synthetic ability to make connections between things that other people don't recognize spontaneously.

- Analytic ability is critical thinking used to analyze and evaluate ideas. The creative individual uses analytic ability to work out the implications of a creative idea and to test it.

- Practical ability is the ability to translate theory into practice and abstract ideas into practical accomplishments. The creative person uses practical ability to sell an idea.

Creativity requires a balance among these three abilities. The person who is only synthetic may come up with innovative ideas, but cannot evaluate or sell them. The person who is only analytic may be an excellent critic of other people's ideas, but is not likely to generate creative ideas. The person who is only practical may be an excellent salesperson but will rely on others for ideas.

The FIPSE grant provides replacement salaries and the financial resources to allow development of these three creative skills in the graduate students through two paths. The first will be the use of existing (but once again rarely utilized) industrial training seminars that have been successfully used to increase creativity in industrial technology groups. Seminars will be arranged through institutions such as the Center for Studies in Creativity at Buffalo State University (SUNY), and 
through individual consultants such as Dr. Ed Sobey, the first Director of the National Inventors Hall of Fame and author of nationally recognized books on teaching inventiveness.

The second method will be through the design and implementation of a course by Professor Ken Vickers in technology market space analysis for identification of opportunities for new devices. This course will be designed to address not only the creativity training issue, but also the need to integrate business framework knowledge into the technical curriculum by attracting business and engineering students into the course through cross listing of the course with those colleges.

It has already been demonstrated that such a cross listing will attract such a mixture of students by a course teaching the concepts of technology entrepreneurship toward the formation of startup technology businesses. This course has been implemented as a team-taught class by Professor John Todd of the College of Business Administration and by Professor Vickers. Business students interested in technology-based businesses sign up for the class, as well as technology students with entrepreneurial personalities. It is expected that this same mixture of students from outside of physics will also enroll in this two-course sequence.

In this course the students will first be formed into small teams, with each team's members selected by the instructor to maximize educational and cultural diversity across all teams. Each of these teams will be given an area of current research strengths in the department to examine. They will first develop an understanding of the science behind the research area. They will then develop knowledge of the types of devices and applications that this research area could impact, and they will research the technology space for current devices that dwell in this space. Next they will examine the device characteristics, market penetration, and pricing structure of these current devices.

With this competitive information in hand, along with the knowledge of the research area's current state of the art capability in the department, they will define a new device that could be fabricated using the department's research capabilities. Each team will project what device characteristics would be required by their new product in order to penetrate the marketplace, including what pricing structure would variations would result in different market size. The final step will be an analysis of the manufacturability of their proposed device, which would result in a determination in the expected cost of production of the devices.

At the completion of each step of teams' investigations, they will give a presentation to the class with the results of their analysis. The other teams will act in the roles of management and will provide feedback to the presenting team, feedback that will accomplish two purposes. The first will be to give presenting team information on how to increase the accuracy of that analysis step. The second purpose will be to give the reviewing teams the opportunity to examine if their own analyses might have the same problems as they see during another presentation.

As a result of this process, the students will gain valuable practice in (1) the creative process of 
product definition and analysis, (2) the integration of business analysis framework with technical product analysis, and (3) the soft skill set necessary to work as a team and to present their complex analyses in an effective management presentation format.

c. Development and implementation of a framework for business and creativity training through a device development and commercialization course based in departmental research strengths.

This strategy will strongly address two of the identified educational needs: integrating traditional physics education with a business framework and integrating traditional physics education with creativity training.

This will be the follow-up course to the device invention course described in Strategy b above. The primary goal of this course, designed and implemented by Professor Greg Salamo of physics, is to reduce to practice the one or two of the proposed devices developed in the device invention course the prior semester. The class will use the information packets from the team analyses to select the most promising possible new device or product for this class to develop through the prototype stage of a commercialization effort.

Students will organize themselves into an operational structure to manage each stage of prototype production under the direction of Professor Salamo. Each organizational element will have the responsibility to assure their portion of the task is successfully accomplished, but will have the authority to request resources from classmates assigned to another organizational element. Each organizational element will have a leader that acts as part of an overall coordinating leadership team for the entire class.

As an illustrative example of how this class would operate, consider the possible attributes of such a course based in nanoscience studies. Picture a business, science and engineering team of students taking a device with design and structure definition completed, including needed parametric and cost performance points for market penetration. Imagine this team organizing themselves into sub-teams to address different aspects of constructing a real device to meet that design document using state of the art research equipment. One sub-team would concentrate growing that structure using molecular beam epitaxy (MBE) and observing surface reconstruction or self-assembled dot formation with an in-situ scanning tunneling microscope (STM). Another sub-team would process the grown substrates into devices accessible from macroscopic systems such as PDAs. Another sub-team would characterize the devices and provide feedback to the fabrication sub-teams. Another sub-team would be taking early prototype data and investigating competing device performance, in the process designing a marketing plan for their device under characterization. And throughout these processes the entire class would be creating the technical literature describing the device.

While nanoscience has been presented in this paper as an illustrative example, the concept can be implemented in any physics department in a course that takes advantage of their primary research 
areas. Clearly, this is an approach with tantalizing possibilities to not only bring state of the art research alive, but to also learn how to produce early commercialization research that could result in products beneficial to society.

A complementary course to this two-course sequence has already been co-developed by Professor Vickers and Professor John Todd of the school of Business Administration under the financial sponsorship of the National Collegiate Inventors and Innovators Alliance (http://www.nciia.org). This course, MGMT 5383 Intra/Entrepeneurship of Technology, addresses the full business process of research to commercialization from a theoretical viewpoint. Students that feel that they have successfully brought a new device to prototype stage can take this third course to help them develop the skills to convert their product from being only a prototype to true early production and the creation of a new technology start-up business.

\section{Evaluation and dissemination}

Professor Ronna Turner of the Office of Research, Measurement, and Evaluation in the College of Education and Health Professions will lead the evaluation. The mission of the evaluation will be to assess four key components of the proposed program: (i) the integration of physics education with a business framework; (ii) the integration of physics traditional coursework with creativity training; (iii) the integration of global perspectives into local technology decisions; and (iv) the integration of soft skill set development with traditional physics educational elements.

The evaluation component is intended to assess the effectiveness of the proposed program in producing successful Physics graduate students whom excel in cognitive, creative, and leadership areas in addition to the obtainment of a broader multidisciplinary academic education. Assessment of the program effectiveness will be based on quantitative objective measures of student characteristics and technical skills, and on perceptional assessments of student abilities by faculty, business members, and employers. Additional information will be obtained for addressing the improvement of the delivery of education within the proposed program. Longitudinal databases will be created for the purposes of assessing change across time for cohort groups within programs, in addition to allowing for comparisons of traditional and non-traditional program participants.

The evaluation is divided into five phases. The first two phases provide for the creation of a longitudinal student database for evaluating program participants and non-participants on the selection of cognitive, academic, and interpersonal characteristics that are hypothesized to be related to the unique training provided by the proposed program. The third phase provides for the creation of a cross-sectional database that will provide a program assessment component as assessed by potential employers. The fourth phase is the creation of a longitudinal database for assessing program participants and non-participants' early career performance and long-term success as perceived by their employers and the graduates, themselves. 
There are several qualitative components to the program evaluation that will be assessed by providing descriptive information for identifying trends and patterns in the data. The quasiexperimental components of the evaluation will be assessed using multivariate analysis of variance procedures for assessing cross-sectional data and repeated measures designs for assessing longitudinal data. Certain baseline measures are being recorded for use as potential covariates because of the inability to incorporate random assignment.

\section{Phase I: Assessment of 'Program Participants' Demographic Data (initiates at Year 0)}

A database composed of demographic, academic, and personal characteristic information will be created for use as a descriptive measure and potential covariate for interpretation of the assessment scores using cognitive, interpersonal, and academic measures obtained in phase II. Data will be obtained from "comparable" students in similar, but more traditional, types of hard science programs for comparisons to data obtained from the participants of the proposed Physics program. Background information such as area of specialization, prior coursework, standardized test performance, ethnicity, gender, academic and professional experiences will be collected.

Phase II: Comprehensive Evaluation of Program Participants (initiates at Year 0)

Program participants and non-program participants in comparable fields will be evaluated on both traditional academic measures and non-traditional interpersonal and cognitive measures. Academic measures such as coursework completed, performance in courses, and professor perception of student strengths and weaknesses will be utilized. The non-academic focus of this phase will be on the assessment of creativity, teamwork and leadership skills, learning styles, global perspective, and interpersonal characteristics. This information will be used for improving the delivery of education, making participant and non-participant comparisons, and assessing change across time for participants within the different programs.

The database will be longitudinal, with an initial baseline assessment obtained through administration of the instruments at student entry into the programs and annual reassessment of performance on the measures at the beginning of each academic year. There will be individualized exit evaluations at the time of completion of the programs. Data will be collected each year for the new cohorts of students entering the programs.

The procedure for storing data will allow for the assessment of growth models for students within a cohort, between cohorts of students in the same program but enrolling in different years, and between cohorts of students in different programs. This process will also allow for evaluation of the effectiveness of individual seminars and special training events implemented in the various programs. The feedback may aid faculty in the evaluation and refinement of the training events for improvement purposes.

Four instruments have already been selected for use in phase II of the evaluation. First, creativity 
will be measured using five creativity scales selected from the Structures of Intellect Creativity Test (SOI-CT). The five scales selected have previously been utilized in research with engineering students and are defined as measuring various types of divergent creative thinking such as the creation of figural relationships, figural transformations, semantic relations, semantic transformations, and symbolic units.

Second, team building and leadership characteristics will be assessed using an instrument created by Murry defined to measure four types of teamwork characteristics. The scales are measures of individual communication preferences and styles, commitment to the creation and maintenance of an integrated work environment, desire to foster a collaborative work environment compared to an individualized environment, and personal action toward modeling a team building and teamwork supportive environment.

Third, interpersonal characteristics will be measured using the Myers-Briggs Personality Inventory (MBTI). The MBTI is designed to assess personal characteristics such as introversion/extroversion, thinking/feeling, sensing/intuition, and judging/perceiving.

Fourth, the Index of Learning Styles (ILS) will be administered to provide feedback regarding students learning styles. Four learning style preferences are assessed: active/reflective, sensing/intuitive, visual/verbal, and sequential/global.

An additional fifth instrument to assess student knowledge and perceptions regarding differences in cultural interactions in the work environment will be created by the evaluators. Observational techniques may need to be incorporated for obtaining an objective measure of students' abilities to interact in a professional and academic environment from a conceptual framework that utilizes a global perspective.

Phase III: Business and Industry Evaluation (initiates at Year 1)

Evaluations by potential business and industry consumers of students produced by the proposed program will be obtained by measuring their perceptions regarding characteristics related to expected job performance. Potential employers who interview program participants will be queried regarding perceptions of strengths, weaknesses, and associated cognitive and interpersonal characteristics of the applicants individually and as compared to their counterparts graduating from more traditional hard science programs. Additionally, representatives of companies expected to hire participants from the proposed program will visit the campus at least once per year and provide feedback on expectations, perceptions, and preferences regarding various program elements. Elements that will be discussed will include required and elective coursework, seminars, traditional and non-traditional training components, faculty expertise, accessibility and/or networked knowledge of unique program characteristics, and effectiveness of the students produced. The needed survey instruments and focus group questions will be developed during the first year and modified as deemed appropriate to feedback from early applications of the 
instruments.

Phase IV: Career Tracking of Program Graduates (initiates with first program graduate)

Employers of students graduating from the proposed program and the more traditional programs will be tracked over time for surveying perceptions of student success. After six months, managers will be surveyed regarding their perceptions of early career effectiveness of the students they hired. These evaluations will include characteristics such as job performance, creativity, interpersonal skills, team building effectiveness, and leadership skills. Follow-up questionnaires will continue to be administered to employers at yearly intervals for five years. The longitudinal tracking of student performance is intended to provide a measure of long-term success and career advancement. Program graduates will be also be surveyed on the same schedule regarding their perceptions of their academic preparation for the current job in which they are employed. The survey instruments are scheduled for development and piloting in the first and second year.

Phase V: Dissemination (initiates at Year 2)

The dissemination of information obtained will be an ongoing process throughout the course of the study. The evolving information obtained and the knowledge gained from the process of completing this grant will be rapidly disseminated via the web, professional journals, and presentations at professional meetings.

The types of evaluations conducted for program development and implementation are commonly limited to qualitative assessments of student, faculty, and business member satisfaction. These types of evaluations do not provide evidence of change or growth in performance areas or skills in which the implementation of new programs is hypothesized to facilitate. The evaluation methods described in this paper provide the mechanisms for assessing growth across time on a variety of cognitive and interpersonal measures. It is hypothesized that this evaluation will provide physics departments across the nation the framework for implementing the proposed educational enrichments in their own departments, rapidly creating the broad supply of next-generation physicists already needed today.

\section{Current implementation status}

The FIPSE proposal from the University of Arkansas, "An Enriched Physics Graduate Education Methodology", was selected for award early in the fall 2000 semester. The targeted group of physics graduate students for first implementation was selected to be academic year 2001-2002 students, defined as any student that entered the Physics Department after May 12 2001.

As in any major change, there are concerns that the new elements introduced may be destructive when implemented instead of constructive. The methods defined in the FIPSE proposal were radical in the light of traditional physics departmental procedures, but they had already been implemented for two 
years as part of the definition of operational procedures in the recently formed interdisciplinary graduate program between engineering and sciences in Microelectronics-Photonics, or microEP (http://www.uark.edu/depts/microep).

Having this educational "proof of concept" on the same campus alleviated some of the concerns of the faculty (especially amongst the physics faculty members that were participants in the microEP program). Even so, there were significant disagreements on the whether or not methods that were working well in the interdisciplinary microEP program would be equally beneficial in a physics department. The central concern expressed in these discussions was based in the time scale of basic science research in physics versus more applied research that is a significant portion of the microEP program.

Full faculty implementation approval was approached in a two-step process. The program elements were first fully communicated to all faculty members through distribution of hardcopy versions of the FIPSE proposal. The PIs of the proposal then presented the program elements and implementation plan to the full faculty at a specially called faculty meeting for discussion and approval. During this meeting, it became clear that the program required further clarification of details and the program was sent to the graduate committee for review, with a recommendation for approval or rejection the expected outcome of the committee action. This committee review was vigorous, and resulted in a recommendation of approval for all program elements except one (the mandatory use of Microsoft Project for research planning). After discussion of the committee's findings and recommendations, the faculty adopted the committee recommendation without modification at the next faculty meeting.

It is the intention of the authors of this paper to continue to report on implementation progress and evaluation results during the three-year life of the grant, including which program elements will be judged to have sufficient benefit to justify departmental funding for continuation.

Bibliography

1. B.Walker, S. Jeng, P. Orkwis, G. Slater, P. Khosla, G. Simites (1998) J. Eng. Ed, 481 - 487.

2. G. Mason, J. Eng. Ed, July 1998, 211-214.

3. Comments of IEEE-USA president John Reinert to Congress (4/1/98) as reported in EE Times, by Robert Bellinger.

4. Interview with Betty White (November 1998), The Boeing Company's director of engineering and technology support and university relations, by Vicky Hendley, ASEE Prism, PP 36-37.

5. Murry, J.W., Jr., \& Stauffacher, K.B. (1999, March 3). Bringing about change by turning your department into a high performance team. A workshop presented at the 8 th Annual International Conference for Chairs, Deans, and Other Organizational Leaders sponsored by The Chair Academy, Long Beach, CA.

6. R. Morgan, P. Reid, and W. Wulf, ASEE May-June Prism, 13 - 17.

7. B. Panitz, ASEE Prism Magazine, May-June 1998, 30 -31.

8. A Tobias, EE Times Fall 1998 College Recruitment

9. B. Poroberts and B. Schmidt, Lucent Technologies, EE Times 1998, August 31, 1998

10. Stein, L. (Ed.) (1975). Style and idea: Selected writings of Arnold Schoenberg (L. Black, Trans.). New York: St. Martin's Press.

11. Barron, F.(1988). Putting creativity to work. In R. J. Sternberg (Ed.), The nature 
12. of creativity (pp. 76-98). New York: Cambridge University Press.

13. Sternberg, R. J. (Ed.). (1988). The nature of creativity: Contemporaryp sychological perspectives. New York: Cambridge University Press.

14. Simonton, D. K. (1984). Genius, creativity, and leadership. Cambridge, MA: Harvard University Press.

15. Findlay, C. S., \& Lumsden, C. J. (1988). The creative mind: Toward an evolutionary theory of discovery and invention. Journal of Social and Biological Structures, 11, 3-55.

16. Hennessey, B. A., \& Amabile, T. M. (1988). The conditions of creativity. In R. J. Sternberg (Ed.), The nature of creativity (pp. 11-38). New York: Cambridge University Press.

17. Finke, R. A. (1990). Creative imagery: Discoveries and inventions in visualization. Hillsdale, NJ: Erlbaum.

18. Feldman, D. H., Csikszentmihalyi, M., \& Gardner, H. (1994). Changing the world: A framework for the study of creativity. Westport, CT: Praeger.

19. Simonton, D. K. (1994). Greatness: Who makes history and why? New York: Guilford.

20. Csikszentmihalyi, M. (1996). Creativity. New York: HarperCollins.

21. Feist, G. J. (1999). The influence of personality on artistic and scientific creativity. In R. J. Sternberg (Ed.), Handbook of creativity (pp. 273-296). New York: Cambridge University Press.

22. Feldman, D. H. (1999). The development of creativity. In R. J. Sternberg (Ed.), Handbook of creativity (pp. 169186). New York: Cambridge University Press.

23. Simonton, D. K. (1997). Creative productivity: A predictive and explanatory model of career trajectories and landmarks. Psychological Review, 104, 66-89.

24. Amabile, T. M. (1996). Creativity in context. Boulder, CO: Westview Sternberg,

25. R. J., \& Lubart, T. I. (1995). Defying the crowd: Cultivating creativity in a culture of conformity. New York: Free Press.

26. Sternberg, R. J., \& Williams, W. M. (1996). Developing creativity in students. Alexandria, VA: Association for Supervision and Curriculum Development.

27. Sternberg, R. J. (1999). A propulsion model of types of creative contributions. Review of General Psychology, 3, 83-100.

\section{KEN VICKERS}

Ken Vickers is a Research Professor in Physics at the University of Arkansas, and has served as Director of the interdisciplinary Microelectronics-Photonics Graduate Program since April 1998. He worked for Texas Instruments from 1977 through March 1998 in integrated circuit fabrication engineering, the last seven years as Engineering Manager of the TI Sherman IC Wafer Fab. Professor Vickers' technical accomplishments before leaving TI included chairmanship of the Sherman Site Technical Council for six years, election to Senior Member Technical Staff, chairmanship of two corporate level worldwide teams, and authorship of twenty-eight issued patents. He received BS and MS degrees in Physics from the University of Arkansas in 1976 and 1978 respectively.

\section{GREG SALAMO}

Greg Salamo is a University Professor of Physics at the University of Arkansas. He leads several interdisciplinary research efforts between universities and industry in photonic materials and semiconductor nanoscience, and has been the leader at the University of Arkansas in promoting interdisciplinary research and education. Dr. Salamo received a BS degree in Physics from Brooklyn College in 1966, an MS degree in Solid State from Purdue University in 1968, and his Ph.D. in Optics from CUNY/Bell Labs in 1973. After a Post-Doc position at the University of Rochester, he joined the faculty of the University of Arkansas in 1975.

\section{RONNA TURNER}

Ronna Turner is an assistant professor of research methods and measurement at the University of ArkansasFayetteville. She is the Associate Director of the Office of Research, Measurement and Evaluation (ORME) and currently conducts research evaluating the effectiveness of systemic change programs on student achievement in the state of Arkansas. Dr. Turner received a B.S. Ed., Mathematics, degree from Southwest Missouri State University in 
1991, a MS Ed., Social Science, degree from Southwest Missouri State University in 1991, and her Ph.D. in Educational Psychology from the University of Illinois in 2000.

Proceedings of the 2001 American Society for Engineering Education Annual Conference \& Exposition 